\title{
Overexpression of Class III $\beta$-tubulin, Sox 2 , and nuclear Survivin is predictive of taxane resistance in patients with stage III ovarian epithelial cancer
}

\author{
Jintong Du ${ }^{1,2 \dagger}$, Bei Li ${ }^{1 \dagger}$, Yingli Fang ${ }^{1}$, Yanguo Liu', Yang Wang ${ }^{1}$, Jisheng $\mathrm{Li}^{1}$, Wen Zhou ${ }^{1}$ and Xiuwen Wang ${ }^{1 *}$
}

\begin{abstract}
Background: Class III $\beta$-tubulin, Sox2, and Survivin play important roles in tumor survival and proliferation. However, the association of these three factors with clinicopathological characteristics, chemoresistance, and survival in patients with ovarian cancer remains controversial.

Methods: We investigated the predictive value and correlation among the expression levels of Class III $\beta$-tubulin, Sox2, and Survivin in 110 patients with stage III ovarian epithelial cancer, including 58 patients who received taxane-based chemotherapy and 52 patients who received non-taxane-based chemotherapy. Expression of these three factors was immunohistochemically examined in 110 ovarian tumor tissues obtained from patients before chemotherapy.

Results: The positive expression rates for Class III $\beta$-tubulin, Sox2, and Survivin in ovarian tumor tissues were $59.09 \%, 61.82 \%$ and $52.73 \%$, respectively. The expression of nuclear Survivin and Class III $\beta$-tubulin was consistent with that of Sox2 ( $p=0.005$ and 0.020 , respectively). Positive expression of Class III $\beta$-tubulin, Sox2, and nuclear Survivin was significantly associated with chemoresistance to taxane-based chemotherapy $(p=0.006,0.007$, and 0.009 , respectively), but not to non-taxane-based chemotherapy. Additionally, overexpression of Class III $\beta$-tubulin, Sox2, and nuclear Survivin predicted poor progression-free survival in patients receiving taxane-based chemotherapy ( $p=0.032,0.005$, and 0.004 , respectively).

Conclusions: These findings suggest that overexpression of Class III $\beta$-tubulin, Sox2, and nuclear Survivin might be predictive of taxane resistance and poor progression-free survival in patients with stage III ovarian epithelial cancer. Expression of these three factors may show positive correlations in these patients.
\end{abstract}

Keywords: Ovarian cancer, Class III $\beta$-tubulin, Sox2, Survivin, Taxane, Resistance, Survival

\section{Background}

Ovarian cancer is regarded as the most lethal gynecologic malignancy and ranks as the seventh leading cause of cancer death among women [1]. The majority of patients with ovarian cancer are diagnosed at an advanced stage. Patients treated with standard therapies such as cytoreductive surgery and chemotherapy often experience tumor progression and poor survival, which may be due to intrinsic or acquired chemoresistance. In the

\footnotetext{
* Correspondence: xiuwenwang12@sdu.edu.cn

${ }^{\dagger}$ Equal contributors

'Department of Chemotherapy, Qilu Hospital of Shandong University, No. 107 Wenhuaxi road, Ji'nan, Shandong 250012, China

Full list of author information is available at the end of the article
}

past few decades, much research has been performed to identify predictive markers for ovarian cancer.

Class III $\beta$-tubulin has been linked to taxane resistance through a reduced microtubule polymerization rate. In 1997, Maria Kavallaris's group first reported altered expression of specific $\beta$-tubulin genes in taxol resistant ovarian tumors and proposed that the class III and IVa isotypes of $\beta$-tubulin may play a role in clinical resistance to paclitaxel [2]. Several recent studies also suggested that the overexpression of Class III $\beta$-tubulin was related to paclitaxel resistance in ovarian cancer cell lines $[3,4]$.

The transcription factor sex-determining region $\mathrm{Y}$ box2 (Sox2), located on chromosome 3q26.3-q27 [5],

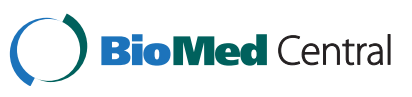

(C) 2015 Du et al. This is an Open Access article distributed under the terms of the Creative Commons Attribution License (http://creativecommons.org/licenses/by/4.0), which permits unrestricted use, distribution, and reproduction in any medium, provided the original work is properly credited. The Creative Commons Public Domain Dedication waiver (http:// creativecommons.org/publicdomain/zero/1.0/) applies to the data made available in this article, unless otherwise stated. 
plays a pivotal role in maintaining self-renewal and pluripotency of cancer stem cells (CSCs) and regulating tumor cell survival [6]. Persistence of CSCs could be detected in mouse ovarian cancer cells after paclitaxel/ carboplatin chemotherapy, and may lead to tumor recurrence [7]. A study using human ovarian cancer cell lines also suggested that the expression of Sox 2 might account for cellular resistance to paclitaxel, cisplatin, and carboplatin [8].

Survivin, the smallest member of the inhibitor of apoptosis protein family, prevents programmed cell death [9]. Similar to Class III $\beta$-tubulin, Survivin also interacts with microtubules of the mitotic spindle to oppose the action of taxane, which blocks cell division by stabilizing microtubules in the G2/M phase [10]. One in vitro study demonstrated that silencing of Survivin could increase the sensitivity of ovarian cancer cells to paclitaxel, but not to cisplatin $[3,11]$.

Interestingly, knockdown of the Sox 2 gene inhibited androgen-independent prostate cancer cell proliferation and induced apoptosis through downregulation of the Survivin gene [12]. Similar results were observed in human non-small-cell lung cancer cells [6]. Furthermore, overexpression of Sox2, induced by upregulation of Survivin, could maintain the survival and homoeostasis of neural stem cells [13]. Additionally, several researchers have reported that the transcriptions of Class III $\beta$ tubulin, Sox2, and Survivin could be induced by a common factor-hypoxia inducible factor-a key intermediate factor in the evolution of cancer [14-17]. These studies underscore the necessity of exploring the correlation between Sox2, its potential target gene Survivin, and Class III $\beta$-tubulin in ovarian cancer.

Although efforts have been made to delineate the relationship between these three factors and ovarian cancer $[3,4,18-28]$ or other carcinomas [29-36], consensus conclusions still could not be reached because of contradictory results. The main reason for such discrepancy is probably the fact that most of these studies incorporated patients with some heterogeneity with respect to (1) clinical stage, (2) surgery patterns, (3) post-operative chemotherapy, (4) receipt of neoadjuvant chemotherapy, (5) evaluated index, (6) mRNA and/or protein level. Any of these factors could account for the unreliable or inconsistent results. Moreover, the correlations among Sox2, Survivin, and Class III $\beta$-tubulin have not been investigated among ovarian cancer. In addition, there are not enough data on the prognostic value of these three factors specifically in Chinese patients.

We performed a retrospective study of patients with stage III ovarian epithelial cancer (SOEC) who were treated with taxane-based or non-taxane-based chemotherapies. We investigated the correlations among Class III $\beta$-tubulin, Sox2, and Survivin, and the relationship between expression of these three factors and clinicopathologic characteristics, chemoresistance, and survival.

\section{Methods}

\section{Patients}

The study was performed using ovarian tumor tissues obtained from 110 consecutive patients with ovarian epithelial cancer in the Tumor Center and Department of Gynecology, Qilu Hospital of Shandong University, between 2000 and 2012. The Ethics Committee of Qilu Hospital approved this protocol, and all patients gave written informed consent. All patients met the following eligibility criteria: (1) classified stage III disease according to International Federation of Gynecologists and Obstetricians and the World Health Organization; (2) received at least two cycles of taxane-based or nontaxane-based chemotherapy beginning 2-3 weeks after primary cytoreductive surgery; (3) did not receive neoadjuvant chemotherapy before primary cytoreductive surgery. Administration of alternative chemotherapy regimens was mainly based on National Comprehensive Cancer Network guidelines, with consideration of anaphylaxis to taxane, the patients' economic factors, and systematic practice variations in different treatment areas. The clinicopathologic characteristics of all patients are listed in Table 1.

All patients received a median of six cycles of chemotherapy using a 21 -day cycle after the primary cytoreductive surgery: 58 patients were treated with taxanebased chemotherapy (defined as the taxane-based group), i.e., PT (135-175 mg/m² paclitaxel or $75 \mathrm{mg} /$ $\mathrm{m}^{2}$ docetaxel on day 1 plus carboplatin dosed with an area under the curve of $4-6$ or $75 \mathrm{mg} / \mathrm{m}^{2}$ cisplatin on day 2), and 52 patients were treated with non-taxanebased chemotherapy (defined as the non-taxane-based group), i.e., PC (carboplatin dosed with an area under the curve of $4-6$ or $75 \mathrm{mg} / \mathrm{m}^{2}$ cisplatin on day 1 plus $750 \mathrm{mg} / \mathrm{m}^{2}$ cyclophosphamide on day 1 ), PAC (50 mg/ $\mathrm{m}^{2}$ cisplatin on day 1 plus $550 \mathrm{mg} / \mathrm{m}^{2}$ cyclophosphamide on day 1 plus $35 \mathrm{mg} / \mathrm{m}^{2}$ doxorubicin on day 1 ), or TC $\left(75 \mathrm{mg} / \mathrm{m}^{2}\right.$ cisplatin on day 1 plus $0.75 \mathrm{mg} / \mathrm{m}^{2}$ topotecan on days $1-5)$.

Response to chemotherapy was evaluated according to the Response Evaluation Criteria in Solid Tumor (RECIST, version 1.1), which includes complete response $(\mathrm{CR})$, partial response (PR), stable disease (SD), and progression of disease (PD). Progression-free survival (PFS) was calculated as the time from the start of chemotherapy to tumor progression or the last follow-up. Overall survival (OS) was calculated as the time from the beginning of chemotherapy to death or the last follow-up [33]. In this study, the median follow-up time was 35 months (range, 7-154 months). 
Table 1 Clinicopathologic characteristics of 110 SOEC patients

\begin{tabular}{|c|c|c|c|c|}
\hline Characteristics & Total no. & Taxane-based group & Non-taxane-based group & $P$ \\
\hline Total no. & 110 & 58 & 52 & \\
\hline Median age (range) & $54(21-76)$ & $54(30-76)$ & $54(21-73)$ & \\
\hline Age (years) & & & & 0.437 \\
\hline$<65$ & 94 & 51 & 43 & \\
\hline$\geq 65$ & 16 & 7 & 9 & \\
\hline Histotype & & & & 0.095 \\
\hline Serous & 84 & 48 & 36 & \\
\hline Others $^{a}$ & 26 & 10 & 16 & \\
\hline Grade & & & & 0.120 \\
\hline G1-2 & 38 & 21 & 17 & \\
\hline G3 & 72 & 37 & 35 & \\
\hline Ascites $(\mathrm{mL})$ & & & & 0.193 \\
\hline$<1000$ & 67 & 32 & 35 & \\
\hline$\geq 1000$ & 43 & 26 & 17 & \\
\hline Residual tumor at surgery $(\mathrm{cm})$ & & & & 0.513 \\
\hline$<1$ & 43 & 21 & 22 & \\
\hline$\geq 1$ & 67 & 37 & 30 & \\
\hline Median cycle of chemotherapy (range) & $6(2-8)$ & $6(2-8)$ & $6(2-8)$ & \\
\hline
\end{tabular}

${ }^{a}$ Ovarian endometrioid carcinoma, 11 cases; ovarian mucous carcinoma, 4 cases; ovarian clear cell carcinoma, 1 case; ovarian malignant mixed müllerian tumor, 1 case; ovarian mixed adenocarcinoma, 9 cases

\section{Immunohistochemistry}

Paraffin-embedded sections of ovarian cancer tissue were obtained during primary cytoreductive surgery for all cases. Slides were deparaffinized, rehydrated, subjected to epitope retrieval, and treated with $\mathrm{H}_{2} \mathrm{O}_{2}$ to block endogenous peroxidase activity. The slides were incubated with normal rabbit or goat serum, followed by incubation with a polyclonal goat anti-Sox2 antibody (AF2018, RD Systems, USA), a monoclonal rabbit anti-Survivin antibody (ab76424, Abcam, USA), and a monoclonal rabbit anti-Class III $\beta$-tubulin antibody (ab52623, Abcam, USA), overnight at $4{ }^{\circ} \mathrm{C}$. Detection was performed using the Streptavidin/Peroxidase kit, Polymer HRP Detection system and DAB kit. Slides were counterstained with hematoxylin and dehydrated with alcohol and xylene. Positive controls were provided by slides taken from glioma tissues for Sox 2 and Class III $\beta$-tubulin, and from colon cancer tissue for Survivin. Negative controls were provided by replacing the primary antibody with phosphate-buffered saline.

The intensity of staining and the percentage of stained cells were evaluated under a light microscope by three independent pathologists without knowledge of clinical data. The intensity of staining was evaluated as follows: 1 = weak staining, $2=$ moderate staining, $3=$ strong staining. The percentage of stained cells was categorized as follows: $0=0 \%$ positive cells, $1=1-10 \%$ positive cells, $2=11-35 \%$ positive cells, $3=36-65 \%$ positive cells, $4=66-100 \%$ positive cells. The total score of stained cells was calculated by the sum of above two scores, where grade $0=0$, grade $1=2-3$, grade $2=4$, grade $3=5$, grade $4=6-7$. Tumor tissues with grade $2-4$ were defined as positive expression and those with grade $0-1$ as negative expression.

\section{Statistical analysis}

Associations between expression of the three factors (Class III $\beta$-tubulin, Sox2, and Survivin) and clinicopathologic characteristics or response to chemotherapy were tested using $\chi^{2}$ test or Fisher's exact test, as appropriate. Survival curves were estimated using the Kaplan-Meier method, and differences in PFS and OS of two subgroups were evaluated using the log-rank test. Cox regression was used for univariate analysis and multivariate analysis to evaluate the prognostic value of the three factors for survival. Only variables with $P<0.10$ in the univariate analysis were included in the multivariate model. All statistical analyses were carried out using SPSS 13.0.

\section{Results}

Expression of Class III $\boldsymbol{\beta}$-tubulin, Sox2, and Survivin

Among the 110 cases, 65 (59.09\%), 68 (61.82\%), and 58 $(52.73 \%)$ were positive for expression of Class III $\beta$ tubulin, Sox2, and Survivin, respectively. As shown in Fig. 1, the expression of Class III $\beta$-tubulin and Sox2 was detected in both the cytoplasm and nucleus in all 

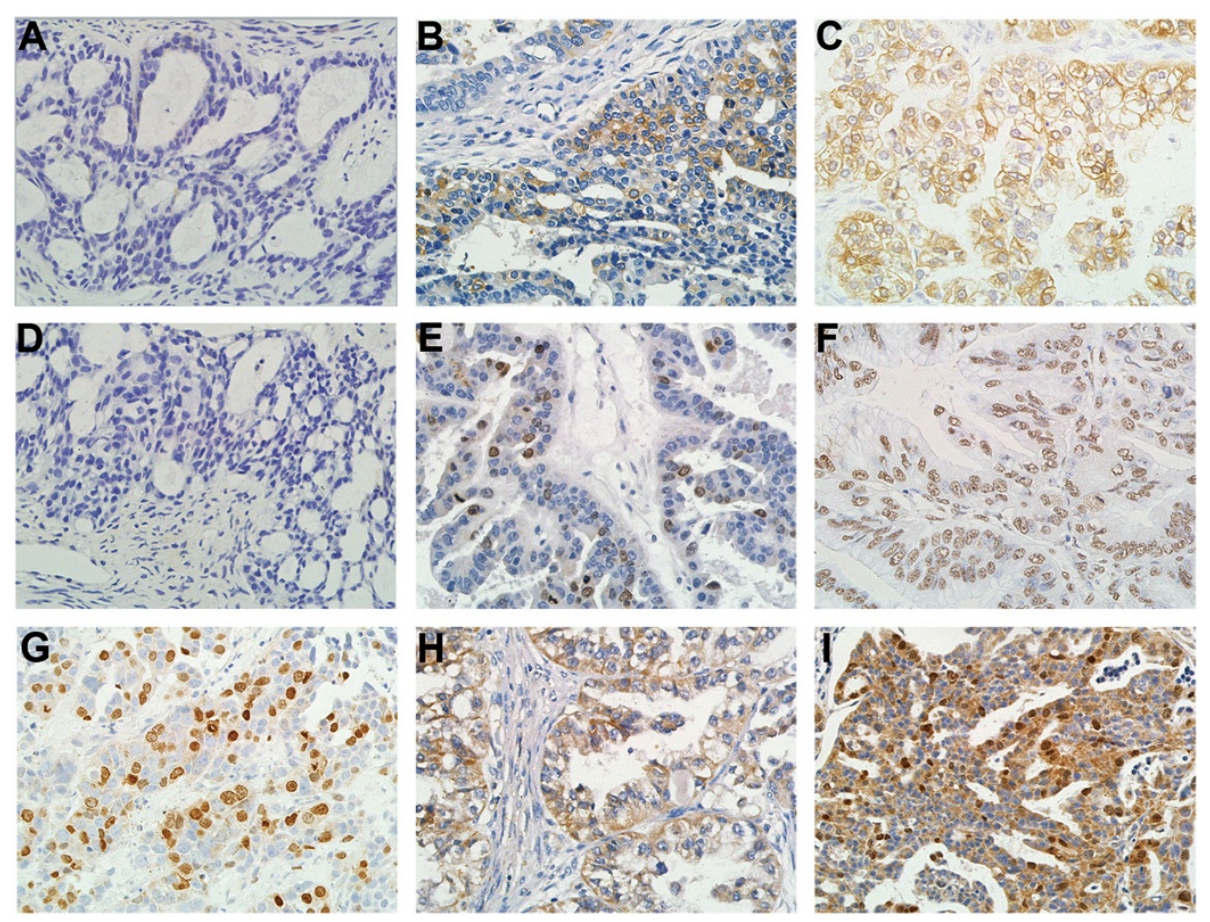

Fig. 1 Representative pictures by immunochemistry for Class III $\beta$-tubulin, Sox2, and Survivin in 110 SOEC patients. Magnification 400x. Class III $\beta$-tubulin expression: (a) negative expression in serous carcinoma, (b) low expression in serous carcinoma, (c) high expression in clear carcinoma. Sox2 expression: (d) negative expression in serous carcinoma, (e) low expression in serous carcinoma, (f) high expression in mucous carcinoma. Survivin expression: (g) only nuclear expression in serous carcinoma, (h) only cytoplasmic expression in serous carcinoma, (i) both nuclear and cytoplasmic expression in serous carcinoma

cases. The expression of Survivin differed among cases: 35 cases $(60.34 \%)$ showed expression only in the nucleus, 9 $(15.52 \%)$ only in the cytoplasm, and 14 (24.14 \%) in both the nucleus and cytoplasm.

It should be mentioned that the expression of nuclear Survivin and Class III $\beta$-tubulin was significantly linearly correlated with that of Sox $2(p=0.005$ and 0.020$)$, as shown in Table 2. However, cytoplasmic Survivin did not show a similar association with Sox $2(p=0.307)$.

\section{Associations between expression of Class III $\beta$-tubulin, Sox2, and Survivin and clinicopathologic characteristics and response to chemotherapy}

As shown in Table 3, expression of Class III $\beta$-tubulin, Sox2, and Survivin was not significantly correlated with age, histotype, grade, ascites, or residual tumor $(p>0.05)$.

The relationships between these three factors and response to chemotherapy are shown in Table 4. In the taxane-based group, positive expression of Class III $\beta$ tubulin, Sox2, and only nuclear Survivin was significantly associated with disease progression $(p=0.006$, 0.007 , and 0.009 , respectively). However, in the nontaxane-based group, no significant associations between expression of these three factors and response to chemotherapy was demonstrated $(p>0.05)$.

\section{Survival analysis}

In the taxane-based group, progression-free survival (PFS) data were available for 57 patients (98.28 \%), and the median PFS was 13 months. The Kaplan-Meier curves in Fig. 2 show that positive expression of Class III $\beta$-tubulin (A), Sox2 (B), and only nuclear Survivin (C)

Table 2 Correlations among Class III $\beta$-tubulin, Sox2, and Survivin in 110 SOEC patients

\begin{tabular}{lllll}
\hline & Total no. & Sox2 positive & Sox2 negative & $P^{\text {a }}$ \\
\hline Nuclear Survivin & & & & $0.005^{*}$ \\
Total no. & 101 & 62 & 39 & \\
Positive & 49 & 37 & 12 & \\
Negative & 52 & 25 & 27 & 0.307 \\
Cytoplasmic Survivin & & & & \\
Total no. & 75 & 39 & 36 & \\
Positive & 23 & 14 & 9 & $0.020^{*}$ \\
Negative & 52 & 25 & 27 & \\
Class III $\beta$-tubulin & & & & \\
Total no. & 110 & 68 & 42 & \\
Positive & 65 & 46 & 19 & \\
Negative & 45 & 22 & 23 & \\
\hline
\end{tabular}

${ }^{\mathrm{a} C a l c u l a t e d}$ by $x^{2}$ test

${ }^{*} P<0.05$ 
Table 3 Associations between expression of Class III $\beta$-tubulin, Sox2, and Survivin and clinicopathologic characteristics in 110 SOEC patients

\begin{tabular}{|c|c|c|c|c|c|c|c|c|}
\hline Characteristics & $\begin{array}{l}\text { Class III } \beta \text {-tubulin } \\
\text { positive/negative }\end{array}$ & $p^{a}$ & $\begin{array}{l}\text { Sox2 positive/ } \\
\text { negative }\end{array}$ & $P^{a}$ & $\begin{array}{l}\text { Only nuclear Survivin positive/ } \\
\text { negative }\end{array}$ & $P^{a}$ & $\begin{array}{l}\text { Only cytoplasmic Survivin } \\
\text { positive/negative }\end{array}$ & $P^{a}$ \\
\hline Total no. & $65 / 45$ & & $68 / 42$ & & $35 / 52$ & & $9 / 52$ & \\
\hline Age (years) & & 0.424 & & 0.620 & & 0.707 & & 1.000 \\
\hline$<65$ & $57 / 37$ & & $59 / 35$ & & $30 / 43$ & & $8 / 43$ & \\
\hline$\geq 65$ & $8 / 8$ & & $9 / 7$ & & $5 / 9$ & & $1 / 9$ & \\
\hline Histotype & & 0.097 & & 0.176 & & 0.733 & & 0.224 \\
\hline Serous & $46 / 38$ & & $49 / 35$ & & $28 / 40$ & & $5 / 40$ & \\
\hline Others & $19 / 7$ & & $19 / 7$ & & $7 / 12$ & & $4 / 12$ & \\
\hline Grade & & 0.101 & & 0.202 & & 0.396 & & 1.000 \\
\hline G1-2 & $19 / 20$ & & $47 / 24$ & & $11 / 21$ & & $3 / 21$ & \\
\hline G3 & $46 / 25$ & & $10 / 5$ & & $24 / 31$ & & $6 / 31$ & \\
\hline Ascites (mL) & & 0.814 & & 0.568 & & 0.371 & & 0.725 \\
\hline$<1000$ & $39 / 28$ & & $40 / 27$ & & $18 / 30$ & & $6 / 30$ & \\
\hline$\geq 1000$ & $26 / 17$ & & $28 / 15$ & & $17 / 19$ & & $3 / 22$ & \\
\hline Residual tumor $(\mathrm{cm})$ & & 0.575 & & 0.299 & & 0.305 & & 0.279 \\
\hline$<1$ & $24 / 19$ & & $24 / 19$ & & $11 / 22$ & & $6 / 22$ & \\
\hline$\geq 1$ & $41 / 26$ & & $44 / 23$ & & $24 / 30$ & & $3 / 30$ & \\
\hline
\end{tabular}

${ }^{a}$ Calculated by $x^{2}$ test, and Fisher's exact test as appropriate

Table 4 Associations between expression of Class III $\beta$-tubulin, Sox2, and Survivin and response to chemotherapy ${ }^{\mathrm{a}}$ in 100 SOEC patients

\begin{tabular}{|c|c|c|c|c|c|c|c|c|}
\hline & \multicolumn{4}{|c|}{ Taxane-based group } & \multicolumn{4}{|c|}{ Non-taxane-based group } \\
\hline & Total no. & $P R$ & $\mathrm{PD}$ & $p^{\mathrm{b}}$ & Total no. & $P R$ & $\mathrm{PD}$ & $p^{b}$ \\
\hline Class III $\beta$-tubulin & & & & $0.006^{*}$ & & & & 0.145 \\
\hline Total no. & 57 & 34 & 23 & & 43 & 33 & 10 & \\
\hline Positive & 34 & 15 & 19 & & 24 & 16 & 8 & \\
\hline Negative & 23 & 19 & 4 & & 19 & 17 & 2 & \\
\hline Sox2 & & & & $0.007^{*}$ & & & & 0.480 \\
\hline Total no. & 57 & 34 & 23 & & 43 & 33 & 10 & \\
\hline Positive & 40 & 19 & 21 & & 25 & 18 & 7 & \\
\hline Negative & 17 & 15 & 2 & & 18 & 15 & 3 & \\
\hline Only nuclear Survivin & & & & $0.009^{*}$ & & & & 0.390 \\
\hline Total no. & 41 & 24 & 17 & & 37 & 30 & 7 & \\
\hline Positive & 19 & 7 & 12 & & 14 & 10 & 4 & \\
\hline Negative & 22 & 17 & 5 & & 23 & 20 & 3 & \\
\hline Only cytoplasmic Survivin & & & & 0.580 & & & & 0.495 \\
\hline Total no. & 27 & 20 & 7 & & 27 & 23 & 4 & \\
\hline Positive & 5 & 3 & 2 & & 4 & 3 & 1 & \\
\hline Negative & 22 & 17 & 5 & & 23 & 20 & 3 & \\
\hline
\end{tabular}

${ }^{a}$ Response to chemotherapy in 100 SOEC patients includes partial response (PR) and progression of disease (PD). There were no patients with complete response (CR) or stable disease (SD)

${ }^{\mathrm{b}}$ Calculated by $x^{2}$ test

${ }^{*} P<0.05$ 


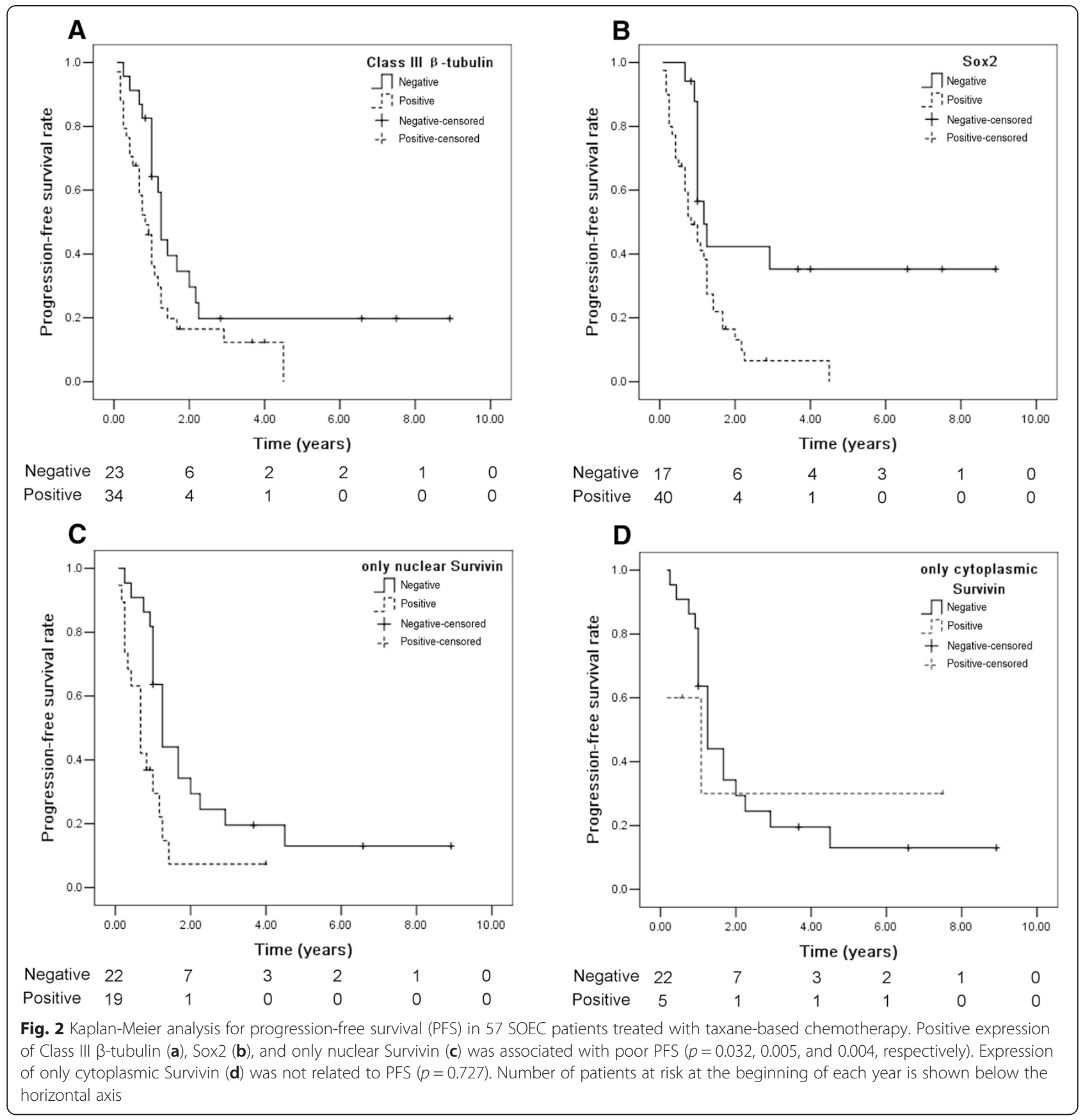

was associated with poor PFS $(p=0.032,0.005$ and 0.004 , respectively). However, expression of only cytoplasmic Survivin (D) was not related to PFS $(p=0.727)$. The median PFS for patients with positive expression of Class III $\beta$-tubulin, Sox2, only nuclear Survivin and only cytoplasmic Survivin was 9.5, 9.5, 8, and 13 months, respectively; the median PFS for non-expressors of Class III $\beta$-tubulin, Sox2, only nuclear Survivin and only cytoplasmic Survivin was $15,12,15$, and 15 months, respectively. The ratio of PFS for expressors and non-expressors of Class III $\beta$-tubulin, Sox2, only nuclear Survivin, and only cytoplasmic Survivin was $1.58,1.58,1.26$, and 1.15 , respectively.

The prognostic value of Class III $\beta$-tubulin, Sox 2 , and Survivin for PFS in the taxane-based group was also evaluated using univariate and multivariate analysis (Table 5). The univariate model indicated that residual tumor diameter $>1 \mathrm{~cm}$ and positive expression of Class III $\beta$-tubulin, Sox2, and nuclear Survivin were associated with shorter PFS $(p=0.001,0.042,0.009$, and 0.047 , respectively). In multivariate analysis, residual tumor, Class III $\beta$-tubulin, and Sox 2 remained as unfavorable 
Table 5 Univariate and multivariate Cox analysis of predictive factors for progression-free survival in 57 SOEC patients treated with taxane-based chemotherapy

\begin{tabular}{|c|c|c|c|c|c|c|}
\hline \multirow[t]{2}{*}{ Variables } & \multicolumn{3}{|l|}{ Univariate } & \multicolumn{3}{|l|}{ Multivariate } \\
\hline & $\overline{\mathrm{HR}}(95 \% \mathrm{Cl})$ & $x^{2}$ & $P$ & $\mathrm{HR}(95 \% \mathrm{Cl})$ & $x^{2}$ & $P$ \\
\hline Age (years) & $0.669(0.282-1.586)$ & 0.835 & 0.361 & - & - & - \\
\hline \multicolumn{7}{|l|}{$<65$} \\
\hline \multicolumn{7}{|l|}{$\geq 65$} \\
\hline Histotype & $1.458(0.720-2.950)$ & 1.099 & 0.295 & - & - & - \\
\hline \multicolumn{7}{|l|}{ Serous } \\
\hline \multicolumn{7}{|l|}{ Others } \\
\hline Grade & $1.244(0.759-2.041)$ & 0.750 & 0.386 & - & - & - \\
\hline \multicolumn{7}{|l|}{ G1-2 } \\
\hline \multicolumn{7}{|l|}{ G3 } \\
\hline Ascites $(\mathrm{mL})$ & $0.990(0.552-1.774)$ & 0.001 & 0.973 & - & - & - \\
\hline \multicolumn{7}{|l|}{$<1000$} \\
\hline \multicolumn{7}{|l|}{$>1000$} \\
\hline Residual tumor (cm) & $3.333(1.650-6.732)$ & 11.266 & $0.001^{*}$ & $3.050(1.499-6.205)$ & 9.471 & $0.002^{*}$ \\
\hline \multicolumn{7}{|l|}{$<1$} \\
\hline \multicolumn{7}{|l|}{$\geq 1$} \\
\hline Class III $\beta$-tubulin & $1.870(1.022-3.423)$ & 4.121 & $0.042^{*}$ & $1.915(1.036-3.538)$ & 4.301 & $0.038^{*}$ \\
\hline \multicolumn{7}{|l|}{ Positive } \\
\hline \multicolumn{7}{|l|}{ Negative } \\
\hline Sox2 & $2.623(1.273-5.407)$ & 6.829 & $0.009^{*}$ & $2.100(1.009-4.373)$ & 3.935 & $0.047^{*}$ \\
\hline \multicolumn{7}{|l|}{ Positive } \\
\hline \multicolumn{7}{|l|}{ Negative } \\
\hline Nuclear Survivin & $1.838(1.009-3.349)$ & 3.959 & $0.047^{*}$ & - & - & - \\
\hline \multicolumn{7}{|l|}{ Positive } \\
\hline \multicolumn{7}{|l|}{ Negative } \\
\hline Cytoplasmic Survivin & $0.958(0.495-1.852)$ & 0.016 & 0.898 & - & - & - \\
\hline \multicolumn{7}{|l|}{ Positive } \\
\hline Negative & & & & & & \\
\hline
\end{tabular}

$H R$ hazard ratios, $\mathrm{Cl}$ confidence interval

${ }^{*} P<0.05$; only variables with $P<0.10$ in the univariate analysis were included in the multivariate model

independent prognostic variables for PFS $(p=0.002$, 0.038 , and 0.047 , respectively).

In the non-taxane-based group, PFS data were available for 41 patients $(78.85 \%)$, and the median PFS was 20 months. Kaplan-Meier curves showed no significant associations between the three proteins and PFS $[p=0.408$, 0.182, 0.386 and 0.965 for Class III $\beta$-tubulin (A), Sox2 (B), only nuclear Survivin $(\mathrm{C})$, and only cytoplasmic Survivin (D), respectively]. The survival curves are shown in Additional file 1: Figure S1.

The overall survival (OS) of 98 patients $(89.09 \%)$ has been followed, and death occurred in 78 cases (79.59 \%). The median OS for patients who received a taxane-based regimen was 55 months, and that for patients who received a non-taxane-based regimen was 58 months. No significant associations were observed between expression of the three proteins and OS of 98 patients using KaplanMeier analysis $[p=0.284,0.138,0.428$, and 0.503 for Class III $\beta$-tubulin (A), Sox2 (B), the only nucear Survivin (C), and the only cytoplasmic Survivin (D), respectively]. The survival curves are shown in Additional file 2: Figure S2.

Potential prognostic factors for OS in all the 98 available patients were also evaluated by univariate and multivariate analysis (Table 6). Significant independent factors were response to chemotherapy, histotype, and residual tumor size $(p<0.0001, p=0.002$, and 0.010 , respectively).

\section{Discussion}

This retrospective study explored the predictive value of expression of Class III $\beta$-tubulin, Sox2, and Survivin, and correlations among these proteins in 110 SOEC patients 
Table 6 Univariate and multivariate Cox analysis of predictive factors for overall survival in 98 SOEC patients

\begin{tabular}{|c|c|c|c|c|c|c|}
\hline \multirow[t]{2}{*}{ Variables } & \multicolumn{3}{|l|}{ Univariate } & \multicolumn{3}{|l|}{ Multivariate } \\
\hline & $\mathrm{HR}(95 \% \mathrm{Cl})$ & $x^{2}$ & $P$ & $\mathrm{HR}(95 \% \mathrm{Cl})$ & $x^{2}$ & $P$ \\
\hline Age (years) & $1.176(0.530-2.611)$ & 0.159 & 0.690 & - & - & - \\
\hline \multicolumn{7}{|l|}{$<65$} \\
\hline \multicolumn{7}{|l|}{$\geq 65$} \\
\hline Histotype & 1.390 (0.969-1.993) & 3.198 & 0.074 & $2.015(1.296-3.134)$ & 9.680 & $0.002^{*}$ \\
\hline \multicolumn{7}{|l|}{ Serous } \\
\hline \multicolumn{7}{|l|}{ Others } \\
\hline Grade & & & & - & - & - \\
\hline G1-2 & $1.318(0.862-2.016)$ & 1.627 & 0.202 & & & \\
\hline \multicolumn{7}{|l|}{ G3 } \\
\hline Ascites $(\mathrm{mL})$ & $1.021(0.576-1.811)$ & 0.005 & 0.943 & - & - & - \\
\hline \multicolumn{7}{|l|}{$<1000$} \\
\hline \multicolumn{7}{|l|}{$>1000$} \\
\hline Residual tumor (cm) & $3.814(1.946-7.476)$ & 15.204 & $<0.0001^{*}$ & $2.736(1.271-5.890)$ & 6.617 & $0.010^{*}$ \\
\hline \multicolumn{7}{|l|}{$<1$} \\
\hline \multicolumn{7}{|l|}{$\geq 1$} \\
\hline Response to chemotherapy & $5.627(3.078-10.289)$ & 31.483 & $<0.0001^{*}$ & $5.318(2.677-10.564)$ & 22.770 & $<0.0001^{*}$ \\
\hline \multicolumn{7}{|l|}{ PR } \\
\hline \multicolumn{7}{|l|}{ PD } \\
\hline Class III $\beta$-tubulin & $1.347(0.776-2.339)$ & 1.119 & 0.290 & - & - & - \\
\hline \multicolumn{7}{|l|}{ Positive } \\
\hline \multicolumn{7}{|l|}{ Negative } \\
\hline Sox2 & $1.537(0.863-2.736)$ & 2.128 & 0.145 & - & - & - \\
\hline \multicolumn{7}{|l|}{ Positive } \\
\hline \multicolumn{7}{|l|}{ Negative } \\
\hline Nuclear Survivin & $1.399(0.813-2.407)$ & 1.472 & 0.225 & - & - & - \\
\hline \multicolumn{7}{|l|}{ Positive } \\
\hline \multicolumn{7}{|l|}{ Negative } \\
\hline Cytoplasmic Survivin & $1.206(0.643-2.261)$ & 0.341 & 0.559 & - & - & - \\
\hline \multicolumn{7}{|l|}{ Positive } \\
\hline Negative & & & & & & \\
\hline
\end{tabular}

$H R$ hazard ratios, $\mathrm{Cl}$ confidence interval

${ }^{*} P<0.05$; only variables with $P<0.10$ in the univariate analysis were included in the multivariate model

who were treated with taxane- or non-taxane-based chemotherapy.

Our results demonstrated that positive expression of Class III $\beta$-tubulin was associated with disease progression in SOEC patients receiving taxane-based therapy, which is in line with previous studies [2, 21]. Furthermore, we found a correlation between overexpression of Class III $\beta$-tubulin and a shorter PFS in SOEC patients treated with taxane-based chemotherapy. Our results also suggested no significant relevance of Class III $\beta$ tubulin expression with response in patients who received non-taxane-based therapy. The Class III $\beta$ tubulin expression was not correlated with OS in the whole patient population. By defining disease progression under chemotherapy as chemoresistance [33, 34, 37], we found that overexpression of Class III $\beta$-tubulin was related to taxane resistance in SOEC patients. However, Ferrandina et al. reported that the Class III $\beta$ tubulin overexpression predicted a shorter OS and had no influence on taxane-based chemotherapy in patients with unresectable ovarian cancer [19]. Thus, Class III $\beta$ tubulin expression may present different biological characteristics in unresectable and resectable patients. Moreover, recent studies reported contradictory results regarding the predictive value of Class III $\beta$-tubulin for OS through immunohistochemistry or qRT-PCR tests in 
patients with stage I-IV ovarian cancer $[4,18,20]$. In general, it appears that different detection methods at the protein or mRNA level, as well as different clinical stages and chemotherapy regimens, may affect the identification of biomarkers.

The positive expression of Sox 2 in the nucleus observed in the present study was in accordance with two previous studies $[38,39]$, but contradicted another study showing Sox2 expression in the cytoplasm [40]. It should be mentioned that we evaluated the predictive value of Sox 2 in SOEC patients who received taxane- or non-taxane-based chemotherapy, which provides more detailed information than studies without subgroup analysis according to the type of chemotherapy [38, 39]. Our results showed that positive expression of Sox 2 was correlated with chemoresistance and a shorter PFS in SOEC patients receiving taxane, whereas Sox2 expression had no significant relevance for response and PFS in patients receiving non-taxane-based chemotherapy. Thus, our study indicated a relationship between Sox2 and taxane-resistance in SOEC patients. However, Zhang et al. did not find an association between Sox 2 and chemoresistance, probably due to heterogeneity of chemotherapies administered [38]. We also found that Sox2 was not a potential biomarker for OS, which was in accordance with data from Zhang's group [38]. In contrast, Pham et al. reported that positive expression of Sox2 predicted a longer survival time in patients with stage II-IV and high-grade ovarian cancer [39]. These distinctions may be explained by differences in clinical stage, histotype, and chemotherapy regimens of patients enrolled in different studies.

Similar to several previous reports [41, 42], the present study indicates that expression of Survivin is predominantly nuclear rather than that of the cytoplasmic. Other studies have reported that expression of Survivin was nearly equivalent in nucleus and cytoplasm $[26,43]$, predominantly in the cytoplasm [27], or only in the cytoplasm [23], which may be due to differences in reagents, tissues and counting methods used. In contrast to these studies, we analyzed the expression of only nuclear Survivin and only cytoplasmic Survivin separately, to exclude any interference of the ratio of nuclear to cytoplasmic Survivin. Kaplan-Meier and univariate analyses showed that overexpression of nuclear Survivin was predictive of poor response to chemotherapy and short PFS in SOEC patients who received taxane-based chemotherapy, but not for those treated with non-taxane-based chemotherapy. However, the predictive value of nuclear Survivin for PFS was not significant in multivariate analysis, perhaps influenced by the sample size and interaction with other factors. In general, we proposed that positive expression of nuclear Survivin might be predictive for taxane-resistance in SOEC patients, expression of cytoplasmic Survivin has no significant predictive value. In most cases, it is the nuclear Survivin, rather than the cytoplasmic Survivin, that sustains cells' pluripotency $[44,45]$, which may support the prognostic value of nuclear staining. Neither nuclear Survivin nor cytoplasmic Survivin was found to be associated with OS in patients. However, previous studies showed contradictory results when evaluating the predictive value of Survivin, which may be due to incorporation of different chemotherapies and clinical stages [3, 23, 24, 26, 28]. Interestingly, Vivas-Mejia et al. demonstrated that Survivin-2B was a prognostic biomarker in taxane-resistant ovarian epithelial cancer [25]. In light of these inconsistent results, the subcellular localization and splicing variants of Survivin should be further investigated.

Our data demonstrated that residual tumor size following primary cytoreductive surgery and histotype were independent predictive factors for PFS and OS in SOEC patients, which is in accordance with the features of favorable tumor biology $[19,46]$. However, expression of Class III $\beta$-tubulin, Sox2, and Survivin showed no relationship with clinicopathologic characteristics and OS. The fact that some SOEC patients received other therapies when tumor progression was found after first-line chemotherapy may have some effect on patient characteristics and the expression of these proteins. Thus, we hypothesized that Class III $\beta$-tubulin, Sox2, and nuclear Survivin may be used to predict chemoresistance, but not the intrinsic tumor aggressiveness and OS.

Several in vitro studies have reported that Survivin is a downstream target of Sox2 $[6,12,13]$. Our results for nuclear Survivin and cytoplasmic Survivin at the protein level in ovarian cancer tissues indicated that nuclear Survivin expression was consist with Sox2 expression. Moreover, Class III $\beta$-tubulin expression also correlated with Sox 2 expression, suggesting the need for further investigation into the clinical relevance of these associations.

The limitations of our study include the small sample size and its retrospective nature. The limited number of patients and missing information of follow-up in terms of PFS for patients who received non-taxane chemotherapies $(21.15 \%)$ may affect the significance of our results. A larger number of cases, and mRNA expression of these potential markers, should be investigated to confirm our findings.

\section{Conclusions}

Overexpression of Class III $\beta$-tubulin, Sox2, and nuclear Survivin might predict taxane resistance and poor progression-free survival in patients with SOEC. Future prospective studies evaluating these markers in SOEC patients should be carried out to determine their clinical potential. 


\section{Additional files}

Additional file 1: Figure S1. Kaplan-Meier analysis for progression-free survival (PFS) in 41 SOEC patients treated with non-taxane-based chemotherapy. There were no significant associations between expression of the three proteins and PFS $[p=0.408,0.182,0.386$ and 0.965 for Class III $\beta$-tubulin (A), Sox2 (B), only nuclear Survivin (C), and only cytoplasmic Survivin (D), respectively]. (JPEG 1010 kb)

Additional file 2: Figure S2. Kaplan-Meier analysis for overall survival (OS) in 98 SOEC patients. There were no significant associations between expression of the three proteins and OS $[p=0.284,0.138,0.428$, and 0.503 for Class III $\beta$-tubulin (A), Sox2 (B), only nuclear Survivin (C), and only cytoplasmic Survivin (D), respectively]. (JPEG $1010 \mathrm{~kb}$ )

\section{Abbreviations}

SOEC: Stage III ovarian epithelial cancer; CSCs: Cancer stem cells;

CR: Complete response; PR: Partial response; SD: Stable disease;

PD: Progression of disease; PFS: Progression-free survival; OS: Overall survival.

\section{Competing interests}

The authors declare that they have no competing interests.

\section{Authors' contributions}

Collected data of patients: JD, BL. Conceived and designed the experiments: $J D, B L, X W, Y F, Y L, J L, Z W$. Performed the experiments: JD, BL, YW, YL. Analyzed the data: JD, LB. Wrote the paper: JD, BL. All authors read and approved the final manuscript.

\section{Acknowledgements}

Financial support by the Wu Jieping Medical Foundation (320.6700.1148) and the Science and Technology Development Plan of Shandong Province (2009GG20002044).

\section{Author details}

1Department of Chemotherapy, Qilu Hospital of Shandong University, No. 107 Wenhuaxi road, Ji'nan, Shandong 250012, China. ${ }^{2}$ Shandong Cancer Hospital, Shandong Academy of Medical Science, Ji'nan, Shandong 250012, China.

\section{Received: 6 May 2014 Accepted: 14 July 2015}

Published online: 23 July 2015

\section{References}

1. Jemal A, Bray F, Center MM, Ferlay J, Ward E, Forman D. Global cancer statistics. CA. 2011;61(2):69-90.

2. Kavallaris M, Kuo DY, Burkhart CA, Regl DL, Norris MD, Haber M, et al. Taxol-resistant epithelial ovarian tumors are associated with altered expression of specific beta-tubulin isotypes. J Clin Invest. 1997;100(5):1282-93.

3. Chen L, Liang L, Yan X, Liu N, Gong L, Pan S, et al. Survivin status affects prognosis and chemosensitivity in epithelial ovarian cancer. Int J Gynecol Cancer. 2013;23(2):256-63.

4. Roque DM, Bellone S, Buza N, Romani C, Cocco E, Bignotti E, et al. Class III beta-tubulin overexpression in ovarian clear cell and serous carcinoma as a maker for poor overall survival after platinum/taxane chemotherapy and sensitivity to patupilone. Am J Obstet Gynecol. 2013;209(1):62 e61-69.

5. Scaffidi $P$, Bianchi ME. Spatially precise DNA bending is an essential activity of the sox2 transcription factor. J Biol Chem. 2001;276(50):47296-302.

6. Chen S, Li X, Lu D, XU Y, Mou W, Wang L, et al. SOX2 regulates apoptosis through MAP4K4-Survivin signaling pathway in human lung cancer cells. Carcinogenesis. 2013;35(3):613-23.

7. Kulkarni-Datar K, Orsulic S, Foster R, Rueda BR. Ovarian tumor initiating cell populations persist following paclitaxel and carboplatin chemotherapy treatment in vivo. Cancer Lett. 2013;399(2):237-46.

8. Bareiss PM, Paczulla A, Wang H, Schairer R, Wiehr S, Kohlhofer U, et al. SOX2 expression associates with stem cell state in human ovarian carcinoma. Cancer Res. 2013;73(17):5544-55.

9. Ambrosini G, Adida C, Altieri DC. A novel anti-apoptosis gene, survivin, expressed in cancer and lymphoma. Nat Med. 1997;3(8):917-21.
10. Deveraux QL, Reed JC. IAP family proteins-suppressors of apoptosis. Genes Dev. 1999;13(3):239-52

11. Zhou J, O'Brate A, Zelnak A, Giannakakou P. Survivin deregulation in beta-tubulin mutant ovarian cancer cells underlies their compromised mitotic response to taxol. Cancer Res. 2004;64(23):8708-14.

12. Lin F, Lin P, Zhao D, Chen Y, Xiao L, Qin W, et al. Sox2 targets cyclinE, p27 and survivin to regulate androgen-independent human prostate cancer cell proliferation and apoptosis. Cell Prolif. 2012;45(3):207-16.

13. Feng R, Zhou S, Liu Y, Song D, Luan Z, Dai X, et al. Sox2 protects neural stem cells from apoptosis via up-regulating survivin expression. Biochem J. 2013:450(3):459-68.

14. Chen YQ, Zhao CL, Li W. Effect of hypoxia-inducible factor-1 alpha on transcription of survivin in non-small cell lung cancer. J Exp Clin Canc Res. 2009;28:29.

15. Semenza GL. Hypoxia-Inducible Factors in Physiology and Medicine. Cell. 2012;148(3):399-408

16. Mathieu J, Zhang Z, Zhou WY, Wang AJ, Heddleston JM, Pinna CMA, et al. HIF Induces Human Embryonic Stem Cell Markers in Cancer Cells. Cancer Res. 2011;71(13):4640-52.

17. Raspaglio G, Filippetti F, Prislei S, Penci R, De Maria I, Cicchillitti L, et al. Hypoxia induces class III beta-tubulin gene expression by HIF-1 alpha binding to its 3' flanking region. Gene. 2008:409(1-2):100-8.

18. Aoki D, Oda Y, Hattori S, Taguchi K, Ohishi Y, Basaki Y, et al. Overexpression of class III beta-tubulin predicts good response to taxane-based chemotherapy in ovarian clear cell adenocarcinoma. Clin Cancer Res. 2009;15(4):1473-80.

19. Ferrandina G, Zannoni GF, Martinelli E, Paglia A, Gallotta V, Mozzetti S, et al. Class III beta-tubulin overexpression is a marker of poor clinical outcome in advanced ovarian cancer patients. Clin Cancer Res. 2006;12(9):2774-9.

20. Roque DM, Buza N, Glasgow M, Bellone S, Bortolomai I, Gasparrini S, et al. Class III beta-tubulin overexpression within the tumor microenvironment is a prognostic biomarker for poor overall survival in ovarian cancer patients treated with neoadjuvant carboplatin/paclitaxel. Clin Exp Metastasis. 2014;31(1):101-10

21. Mozzetti S, Ferlini C, Concolino P, Filippetti F, Raspaglio G, Prislei S, et al. Class III beta-tubulin overexpression is a prominent mechanism of paclitaxel resistance in ovarian cancer patients. Clin Cancer Res. 2005:11(1):298-305.

22. Nachmias B, Ashhab Y, Ben-Yehuda D. The inhibitor of apoptosis protein family (IAPs): an emerging therapeutic target in cancer. Semin Cancer Biol. 2004;14(4):231-43.

23. Zaffaroni N, Pennati M, Colella G, Perego P, Supino R, Gatti L, et al. Expression of the anti-apoptotic gene survivin correlates with taxol resistance in human ovarian cancer. Cell Mol Life Sci. 2002;59(8):1406-12

24. Cohen C, Lohmann CM, Cotsonis G, Lawson D, Santoianni R. Survivin expression in ovarian carcinoma: correlation with apoptotic markers and prognosis. Mod Pathol. 2003;16(6):574-83.

25. Vivas-Mejia PE, Rodriguez-Aguayo C, Han HD, Shahzad MM, Valiyeva F, Shibayama $M$, et al. Silencing survivin splice variant 2B leads to antitumor activity in taxane-resistant ovarian cancer. Clin Cancer Res. 2011:17(11):3716-26

26. Kleinberg L, Florenes VA, Silins I, Haug K, Trope CG, Nesland JM, et al. Nuclear expression of survivin is associated with improved survival in metastatic ovarian carcinoma. Cancer. 2007;109(2):228-38.

27. Ferrandina G, Legge F, Martinelli E, Ranelletti FO, Zannoni GF, Lauriola L, et al. Survivin expression in ovarian cancer and its correlation with clinico-pathological, surgical and apoptosis-related parameters. Br J Cancer 2005:92(2):271-7.

28. Felisiak-Golabek A, Rembiszewska A, Rzepecka IK, Szafron L, Madry R, Murawska $M$, et al. Nuclear survivin expression is a positive prognostic factor in taxane-platinum-treated ovarian cancer patients. J Ovarian Res. 2011;4(1):20

29. Saigusa S, Mohri Y, Ohi M, Toiyama Y, Ishino Y, Okugawa Y, et al. Podoplanin and SOX2 expression in esophageal squamous cell carcinoma after neoadjuvant chemo-radiotherapy. Oncol Rep. 2011;26(5):1069-74.

30. Zhu ML, Horbinski CM, Garzotto M, Qian DZ, Beer TM, Kyprianou N. Tubulin-targeting chemotherapy impairs androgen receptor activity in prostate cancer. Cancer Res. 2010;70(20):7992-8002.

31. Mariani M, Zannoni GF, Sioletic S, Sieber S, Martino C, Martinelli E, et al. Gender influences the class III and V beta-tubulin ability to predict poor outcome in colorectal cancer. Clin Cancer Res. 2012;18(10):2964-75.

32. Urano N, Fujiwara Y, Doki Y, Kim SJ, Miyoshi Y, Noguchi S, et al. Clinical significance of class III beta-tubulin expression and its predictive value for 
resistance to docetaxel-based chemotherapy in gastric cancer. Int J Oncol. 2006;28(2):375-81.

33. Seve P, Isaac S, Tredan O, Souquet PJ, Pacheco Y, Perol M, et al. Expression of class III \{beta\}-tubulin is predictive of patient outcome in patients with non-small cell lung cancer receiving vinorelbine-based chemotherapy. Clin Cancer Res. 2005;11(15):5481-6.

34. Seve P, Mackey J, Isaac S, Tredan O, Souquet PJ, Perol M, et al. Class III beta-tubulin expression in tumor cells predicts response and outcome in patients with non-small cell lung cancer receiving paclitaxel. Mol Cancer Ther. 2005;4(12):2001-7.

35. Saura C, Tseng LM, Chan S, Chacko RT, Campone M, Manikhas A, et al. Neoadjuvant doxorubicin/cyclophosphamide followed by ixabepilone or paclitaxel in early stage breast cancer and evaluation of betalll-tubulin expression as a predictive marker. Oncologist. 2013;18(7):787-94.

36. Saigusa S, Tanaka K, Toiyama Y, Yokoe T, Okugawa Y, loue Y, et al. Correlation of CD133, OCT4, and SOX2 in rectal cancer and their association with distant recurrence after chemoradiotherapy. Ann Surg Oncol. 2009;16(12):3488-98.

37. De Stefano I, Zannoni GF, Prisco MG, Fagotti A, Tortorella L, Vizzielli G, et al. Cytoplasmic expression of estrogen receptor beta (ERbeta) predicts poor clinical outcome in advanced serous ovarian cancer. Gynecol Oncol. 2011;122(3):573-9.

38. Zhang J, Chang DY, Mercado-Uribe I, Liu J. Sex-determining region Y-box 2 expression predicts poor prognosis in human ovarian carcinoma. Hum Pathol. 2012;43(9):1405-12.

39. Pham DL, Scheble V, Bareiss P, Fischer A, Beschorner C, Adam A, et al. SOX2 expression and prognostic significance in ovarian carcinoma. Int J Gynecol Pathol. 2013:32(4):358-67.

40. Ye F, Li Y, Hu Y, Zhou C, Hu Y, Chen H. Expression of Sox2 in human ovarian epithelial carcinoma. J Cancer Res Clin Oncol. 2011;137(1):131-137.

41. Yoshida H, Ishiko O, Sumi T, Matsumoto Y, Ogita S. Survivin, bcl-2 and matrix metalloproteinase-2 enhance progression of clear cell- and serous-type ovarian carcinomas. Int J Oncol. 2001;19(3):537-42.

42. Komuro Y, Watanabe T, Tsurita G, Muto T, Nagawa H. Survivin expression in ovarian carcinoma: correlation with apoptotic markers and prognosis. Mod Pathol. 2004;17(2):264.

43. Felisiak-Golabek A, Rembiszewska A, Rzepecka I, Szafron L, Madry R, Murawska M, et al. Nuclear survivin expression is a positive prognostic factor in taxane-platinum-treated ovarian cancer patients. J Ovarian Res. 2011:4(1):1-9.

44. Li FZ, Yang J, Ramnath N, Javle MM, Tan DF. Nuclear or cytoplasmic expression of survivin: What is the significance? Int I Cancer. 2005;114(4):509-12.

45. Li FZ. Survivin study: What is the next wave? J Cell Physiol. 2003;197(1):8-29.

46. Markman M. Concept of optimal surgical cytoreduction in advanced ovarian cancer: a brief critique and a call for action. J Clin Oncol. 2007;25(27):4168-70.

\section{Submit your next manuscript to BioMed Central and take full advantage of:}

- Convenient online submission

- Thorough peer review

- No space constraints or color figure charges

- Immediate publication on acceptance

- Inclusion in PubMed, CAS, Scopus and Google Scholar

- Research which is freely available for redistribution 